\title{
EFFECT OF THREE COMPONENT AVIATION-TURBINE FUEL, BIODIESEL AND N-BUTANOL BLENDS ON PERFORMANCE EFFICIENCY AND EMISSIONS OF DIESEL ENGINE
}

\author{
Tomas Mickevicius, Audrius Zunda \\ Vytautas Magnus University, Lithuania \\ tomas.mickevicius1@vdu.lt, audrius.zunda@vdu.lt
}

\begin{abstract}
The article presents the test results of a single-cylinder, four-stroke diesel engine operating with jetbiodiesel fuel (J5) blend and its various blends J5Bu5, J5Bu10 and J5Bu15 with n-butanol (Bu). The three biofuel blends were prepared by mixing 95vol\% J5/5vol\% Bu, 90vol\% J5/10\% Bu and 85vol\% J5/15vol\% Bu, respectively. Load characteristics were taken at the engine speed of $n=2000 \mathrm{rpm}$, which corresponds to maximum torque mode. The air mass and fuel mass consumption along with $\mathrm{CO}, \mathrm{CO}_{2}, \mathrm{NO}, \mathrm{NO}_{2}, \mathrm{NO}_{\mathrm{X}}$ emissions and smoke of the exhaust were measured at engine load gradually increased up to maximum. Engine performance parameters and emissions of the exhaust were analysed and compared for various engine loads and fuel blends used in these experiments. Analysis of the obtained data shows that the engine operated most efficiently with a minimum brake specific fuel consumption, when running with the fuel J5 blend, at over the whole load range. Whereas at low engine mode, the highest fuel consumption was measured for biofuel J5Bu15 blend. The lowest emission of carbon oxide (CO) was measured, when operating with the highest concentration biofuel J5Bu15 blend, at full engine load. Maximum NOx emissions (1817 ppm) were measured for the maximum engine torque mode, when running with fuel J5 blend. The amount of NOx produced from combustion of blend J5Bu15 was $10.6 \%$ lower than that measured, when running at the same test conditions with fuel J5 blend. Minimum smoke opacity was also obtained, when fuelling it with fuel blend J5Bu15 at maximum engine torque mode.
\end{abstract}

Keywords: diesel engine, aviation-turbine fuel, biodiesel, performance, emissions, smoke opacity.

\section{Introduction}

The growing demand and volume of transport increases emissions from combustion in internal combustion engines, which pollute the environment and contribute to the atmospheric greenhouse effect. The transport and agriculture sectors are among the largest consumers of fossil-origin fuels and their contribution to the environmental pollution $[1 ; 2]$. Diesel fuel is currently one of the most popular energy-types used in the transport sector. Consumption of the diesel fuel has been growing steadily over the last two decades. The increased consumption of diesel fuel can be explained by the fact that diesel engines operate more efficiently consuming relatively less fuel to produce a unit of effective power and, therefore, less polluting the environment compared to petrol-powered ones. Transport and its emissions have a significant impact on the air quality and human health [3].

Diesel engines are designed to run on traditional mineral fuels; therefore, the rise of various technical problems may occur when powering them with biofuels or alternative fuels. The research results of many scientists have shown the potential of using aviation-turbine fuel for diesel engine fuelling without significant changes in the engine performance and efficiency indicators. Unfortunately, the use of aviation fuel possessing lower density, viscosity, and poorer lubricity properties remains not fully investigated compared to diesel fuel that requires long-term experimental tests to reveal the potential effects on the reliability of the fuel injection system and its elements. Biodiesel (RME) added to aviation fuel not only improves the cetane number, but also changes the carbon to hydrogen atom ratio that reduces the net calorific value, the amount of polycyclic and aromatic substances, and improves lubricating properties of the fuel [4]. Low-carbon alternative and renewable fuels are environment-friendly and locally available therefore can be used to replace the mineral fuels because the reserves of crude-oil decline rapidly. NATO has made a joint decision to use a single fuel on military aircraft, and in all the ground-based vehicles and power generators. This policy is called a single fuel concept (SFC). The main objectives of this decision are significant reduction of logistical problems in case of war and more effective NATO operation in the time of peace [5]. Jet (JP-8) fuel is a military kerosene turbine fuel made from civilian (Jet A-1) fuel and widely used by the United States Air Force and Europe. Aviation turbine fuel is extracted almost exclusively from the kerosene fraction of crude oil, the distillation points of which are between the gasoline fraction and the diesel fraction.

The authors investigate effects of diesel fuel (B5), turbine type JP-8 fuel and its 5 vol\%, 10 vol\%, $20 \mathrm{vol} \%$, and $30 \mathrm{vol} \%$ blends with rapeseed oil methyl ester (RME) at the start of injection, ignition 
delay, combustion history, heat release, engine performance, and exhaust emissions. The engine performance parameters were examined at light 15\% (1400 rpm) and 10\% (2200 rpm), medium 50\%, and high 100\% loads and two speeds. They found that the autoignition delay and the maximum heat release rate decreased, maximum cylinder pressure, and pressure gradients increased, whereas the brake specific fuel consumption changed little and the brake thermal efficiency was 1.0-3.6\% higher, when running with fuel blends J5 to J30 at rated speed compared with the data measured with neat jet fuel. The NOx emissions increased slightly, but the CO, THC emissions, and smoke opacity boosted up significantly, when using jet fuel blend J10 with a smooth reduction of unburned hydrocarbons for jetbiodiesel fuel blends with higher CN ratings. Operation at a full (100\%) load with fuel blend J10 produced more $\mathrm{CO}$ and exhaust smoke, whereas the combustion of identical fuel blend B10 showed the reverse trends, reducing both pollutants at both engine speeds [6].

The authors tested a single-cylinder diesel engine operating with pure JP-8 and JP-8 fuel blended with $10 \mathrm{vol} \%, 30 \mathrm{vol} \%$ and $50 \mathrm{vol} \%$ of sunflower and olive oil. They found that using of both biofuels reduced the PM emissions, but the $\mathrm{HC}$ and $\mathrm{CO}$ emissions almost did not change due to the added biodiesel. Nitric oxide NO and NOx emissions decreased at low (10 vol\%) additions, but the NOx emissions increased at high $50 \mathrm{vol} \%$ percentages of biodiesel in the fuel blend [7].

Ethanol, methanol, and butanol are currently the most popular alcoholic fuels used in internal combustion engines around the world. Higher oxygen content in alcoholic fuels than that in mineral fuels may result in lower calorific value of the biofuels. However, these fuels need less air-borne oxygen to burn the fuel completely and thus can contribute better quality of the environment. The elemental composition of alcoholic fuels makes it possible to reduce the amount of smoke (soot), carbon monoxide $\mathrm{CO}$, carbon dioxide $\mathrm{CO}_{2}$ and aldehydes emitted from diesel engines [8]. A study conducted a comparative analysis of performance and emissions characteristics of aviation fuel (Jet A-1) and butanol/Jet A-1 fuel (B10) blend. The authors found that the fuel consumption and specific fuel consumption are slightly higher for the blend with butanol, compared to Jet A-1 fuel. This is due to the lower calorific value for the fuel blend. The values of carbon monoxide $(\mathrm{CO})$, carbon dioxide $\left(\mathrm{CO}_{2}\right)$ and nitrogen oxides (NOx) emissions for fuel B10 blend were slightly lower, compared to the cases of using Jet A-1 fuel [9].

Using fuel blends with a higher content of biodiesel, changes the technical properties of the fuel: increase density, viscosity, decrease calorific value, cetane number, freezing temperature, etc. These indicators have the impact on the biofuel supply and injection characteristics, the quality of the combustible mixture that, in turn, has influence on the diesel engine performance and ecological indicators [10]. Experiments were conducted at 7.5, 11.25, 15 and $18.75 \mathrm{Nm}$ engine loads and at maximum torque speed $\left(2200 \mathrm{~min}^{-1}\right)$ in a single cylinder, naturally aspirated and direct injection diesel engine. The authors investigated aviation (JP-8) fuel and sunflower methyl ester blend effects on the incylinder pressure, ignition delay period, engine performance and exhaust emissions. It was found that NOx emissions increased with the increase of the amount of biodiesel in the test fuels. As the engine load increases, the specific fuel consumptions decrease for all test fuels. $\mathrm{CO}$ emissions decreased, as the amount of biodiesel fuel increased in the test fuels. Consequently, it was observed that JP-8 and biodiesel fuel mixtures can easily and efficiently be used in diesel engines [11].

Whereas RME added to jet fuel not only improves the cetane number, but it also modifies the carbon-to-hydrogen ratio, provides fuel-bound oxygen, reduces net heating value, the content of polycyclic aromatics, and improves lubricity of the fuel $[12,13]$. Despite a large number of studies conducted in optically-accessible, single cylinder engines, a spherical vessel, laboratory furnaces, burners, and afterburners, there is a lack of works on a diesel engine powered with aviation-turbine fuel, biodiesel and n-butanol blends. It should be noted that biodiesel provides excellent lubricity to the fuel injection system that can reduce excessive wear of precision nozzle-needle-valve parts, which may cause a long-term use of a lighter aviation turbine fuel. In addition, a new important factor comes into action, since mixing of RME with jet fuel provides fuel - oxygen, which helps complete combustion of the fuel-rich mixture.

The purpose of the research is to investigate the influence of three-component fuel blends aiming to improve the efficiency of a diesel engine and reduce emissions of the exhaust. 


\section{Materials and methods}

Experimental research was carried out in the fuel equipment testing laboratory of the Power and Transport Machinery Engineering Institute at the Faculty of Agricultural Engineering of the Vytautas Magnus University - Agricultural Academy. For stroke, one cylinder, direct injection, air cooled „ORUVA FL 511" diesel engine was used for these experiments. The technical characteristics of the experimental engine are listed in Table 1.

Engine FL 511 specifications

\begin{tabular}{|l|l|}
\hline Type & Deutz F1L 511 \\
\hline Operating principle & 4 stroke \\
\hline Number of cylinders & one cylinder \\
\hline Bore, $\mathrm{mm}$ & 100 \\
\hline Stroke, mm & 105 \\
\hline Swept volume, cm3 & 825 \\
\hline Compression ratio & 17 \\
\hline $\begin{array}{l}\text { Injection timing advance in CADs } \\
\text { BTDC }\end{array}$ & $24^{\circ}$ \\
\hline Maximum power (at 3000 rpm), kW & $12.8 \pm 5 \%$ \\
\hline Injection pressure, bar & 175 \\
\hline Fuel consumption, g. $\mathrm{kWh}^{-1}$ & $255 \pm 5 \%$ \\
\hline Rated speed, rpm & 3000 \\
\hline Engine weight, $\mathrm{kg}$ & 135 \\
\hline
\end{tabular}

At first, engine tests have been conducted by using jet-biodiesel fuel blend prepared by mixing RME and JP-A1 fuel in the following proportion by volume 5/95 (J5). After all load characteristics were taken of the engine performance on the jet-biodiesel fuel (J5), three blends with jet-biodiesel fuel (J5) and $\mathrm{n}$-butanol $(\mathrm{Bu})$ were prepared by mixing in various volumetric ratios $95 \% \mathrm{~J} 5$ and $5 \% \mathrm{Bu}(\mathrm{J} 5 \mathrm{Bu} 5)$, $90 \% \mathrm{~J} 5$ and $10 \% \mathrm{Bu}(\mathrm{JBu} 10)$ and $85 \% \mathrm{~J} 5$ and $15 \% \mathrm{Bu}(\mathrm{J} 5 \mathrm{Bu} 15)$. The properties of the tested fuels and its blends are presented in Table 2.

The engine torque was measured with an eddy current dynamometer with a definition rate of $\pm 0.1 \mathrm{Nm}$ and the rotation speed with the mechanical meter with a definition rate of $\pm 2 \mathrm{rpm}$.

The amounts of nitric oxide $\mathrm{NO}(\mathrm{ppm})$, nitrogen dioxide $\mathrm{NO}_{2}(\mathrm{ppm})$, carbon monoxide $\mathrm{CO}(\mathrm{ppm})$ and total unburned hydrocarbons $\mathrm{HC}(\mathrm{ppm})$ in the exhausts were measured with the Testo $350 \mathrm{XL}$ gas analyser. Total emissions of nitrogen oxides NOx were determined as a sum of both $\mathrm{NO}$ and $\mathrm{NO}_{2}$ gases. Total NOx emissions were determined as a sum of both $\mathrm{NO}$ and $\mathrm{NO}_{2}$ pollutants with an accuracy of $\pm 5 \mathrm{ppm}$.

The exhaust opacity (\%) was measured with a Bosch RTT 100/RTT 110 opacity-meter with an accuracy of $\pm 0.1^{\circ}$.

Table 2

Properties of JP-A1 fuel, rapeseed oil methyl ester (RME) and n-butanol

\begin{tabular}{|l|c|c|c|}
\hline Property parameters & JP-A1 & RME & n-butanol \\
\hline Density at $15^{\circ} \mathrm{C}, \mathrm{kg} \cdot \mathrm{m}^{-3}$ & 797.2 & 884.7 & 802 \\
\hline Kinematic viscosity at $40^{\circ} \mathrm{C}, \mathrm{mm}^{2} \cdot \mathrm{s}^{-1}$ & 4.0 & 4.8 & 2.63 \\
\hline Lubricity, corrected wsd, $1.4 \mathrm{~lm}$ at $60^{\circ}$ & 611 & 205 & 591 \\
\hline Cetane number & 42,3 & 53.4 & 25 \\
\hline Oxygen content, max wt.\% & - & 10.9 & 21,58 \\
\hline Carbon-to-hydrogen ratio $(\mathrm{C} / \mathrm{H})$ & 6.13 & 6.48 & 4.80 \\
\hline Net heating value, $\mathrm{MJ} \cdot \mathrm{kg}^{-1}$ & 43.30 & 37.23 & 33.08 \\
\hline Stoichiometric air/fuel ratio, $\mathrm{kg} \cdot \mathrm{kg}^{-1}$ & 14.84 & 12.62 & 11.2 \\
\hline
\end{tabular}

The measuring rages of the apparatus used, accuracies of the measured experimental data of the engine performance and exhaust emission parameters and the uncertainties of the calculated test results (power, fuel consumption etc.) are listed in Table 3. 
Accuracy of the measured engine performance and emission parameters

Table 3 and uncertainty of the computed experimental results

\begin{tabular}{|l|c|c|}
\hline \multicolumn{1}{|c|}{ Parameter } & Measuring range & Accuracy \\
\hline Torque & $0-60 \mathrm{Nm}$ & $\pm 1.5 \%$ \\
\hline Speed & $150-3000 \mathrm{rpm}$ & $\pm 0.5 \%$ \\
\hline $\mathrm{NO}$ & $0-3000 \mathrm{ppm}$ & $5 \%$ \\
\hline $\mathrm{NO}_{2}$ & $0-500 \mathrm{ppm}$ & $5 \%$ \\
\hline $\mathrm{CO}$ & $0-10000 \mathrm{ppm}$ & $5 \%$ \\
\hline $\mathrm{CO}_{2}$ & $0-50 \%$ & $1 \%$ \\
\hline Smoke density & $0-100 \%$ & $1.5 \%$ \\
\hline Engine power output & - & \pm 1 \\
\hline Fuel mass flow rate & - & \pm 0.5 \\
\hline Brake specific fuel consumption & - & \pm 1.5 \\
\hline Brake thermal efficiency & - & \pm 1.5 \\
\hline
\end{tabular}

The engine characteristics were determined, when it was driven by a gradually increasing load and a constant engine speed of $2000 \mathrm{rpm}$. To improve reliability of the measured data the tests have been repeated no less than three times.

\section{Results and discussion}

Fig. 1 shows the fuel consumption per hour and the brake specific fuel consumption (BSFC) variations as a function of engine load. Alterations of the combustion process have effect on the engine economy. Under the same operating conditions, the fuel consumption, when the engine has been operating on jet-biodiesel fuel and its blend with n-butanol, has been little higher compared to the engine operating on jet-biodiesel fuel (J5) blend. It has to be noted that the change of BSFC has been decreasing, while the engine load was increasing (Fig. 1). It is seen, when the engine is running on oxygenated biofuel blends J5Bu5, J5Bu10 and J5Bu15, at low load, the brake specific fuel consumption slightly increased by $1.1 \%, 2.3 \%$ and $4.5 \%$, respectively. When operating on biofuel J5Bu15 blend, the brake thermal efficiency of the diesel engine, decreases by $1 \%$ (Fig. 2).
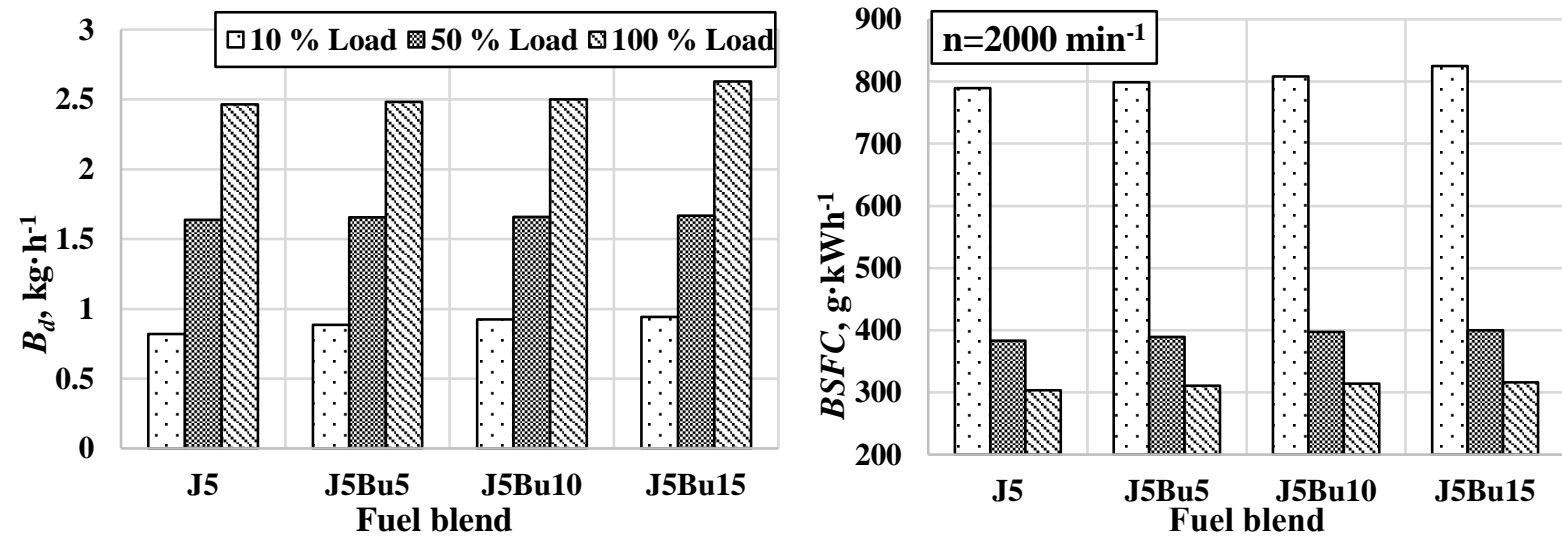

Fig. 1. Fuel consumption per hour $\left(B_{d}\right)$ and brake specific fuel consumption $(B S F C)$ as a function of engine load at $2000 \mathrm{~min}^{-1}$

At full engine load, the brake specific fuel consumption changing tendencies remain similar. When operating on the three-component biofuel J5Bu5-J5Bu15 blends, BSFC increased by 2.4-4.1\%, respectively, in comparison with engine running on fuel $\mathrm{J} 5$ blend. The increased fuel consumption of biofuel J5Bu5-J5Bu15 blends may be attributed reasonably to the lower net heating value of oxygen blends. In case of using the three-component biofuel J5Bu5-J5Bu15 blends, the brake thermal efficiency decreased by $0.4-1.0 \%$ in comparison to the engine running on fuel $\mathrm{J} 5$ blend. The decrease of the brake thermal efficiency in this case can be explained by the fact that it is the mostly affected by their reduced cetane number and the larger latent heat of vaporization of butanol, as the latter suppresses the auto ignition and combustion processes in the cylinder. 
The nitrogen oxides are formed outside the flame front at high temperatures, with free nitrogen atoms reacting with excess oxygen in the combustion chamber by a complex chain reaction. The total emissions of nitrogen oxide amount in the combustion depends more on the maximum process temperature because the reaction is endothermic and not directly related to the combustion processes of the mixture. The variation of total emissions of nitrogen oxides $\left(\mathrm{NO}_{\mathrm{x}}\right)$ as a function of engine load and different fuel blends is presented in Fig. 2. When the engine is running at the average engine load, using of oxygenated biofuel blends J5Bu5, J5Bu10 and J5Bu15, the total emissions of nitrogen oxides reduce by $7.9 \%, 5.6 \%$ and $15.8 \%$, respectively.

The total emission of nitrogen oxide scales up, when the load of the engine increases. In case at full engine load and use biofuel J5Bu5, J5Bu10 and J5Bu15 blends, the total emission of $\mathrm{NO}_{\mathrm{x}}$ decreased by $3.5 \%, 9.2 \%$ and $10.6 \%$, respectively, in comparison with the engine running on fuel $\mathrm{J} 5$ blend. The decrease in total emission of nitrogen oxides can be explained by the lower gas pressure and temperature in the cylinder, as the combustion and heat release processes moved towards the direction of the expansion stroke. The pressure and temperature of the gas burning in a large volume of the cylinder are lower, which, in turn, conditions the lower degree of nitrogen oxide emission. Butanol-diesel blends also show this behaviour, as butanol concentration increased, the NOx, and $\mathrm{CO}$ emissions decreased, while unburned $\mathrm{HC}$ emissions, $B S F C$, and BTE increased as compared to diesel [15].
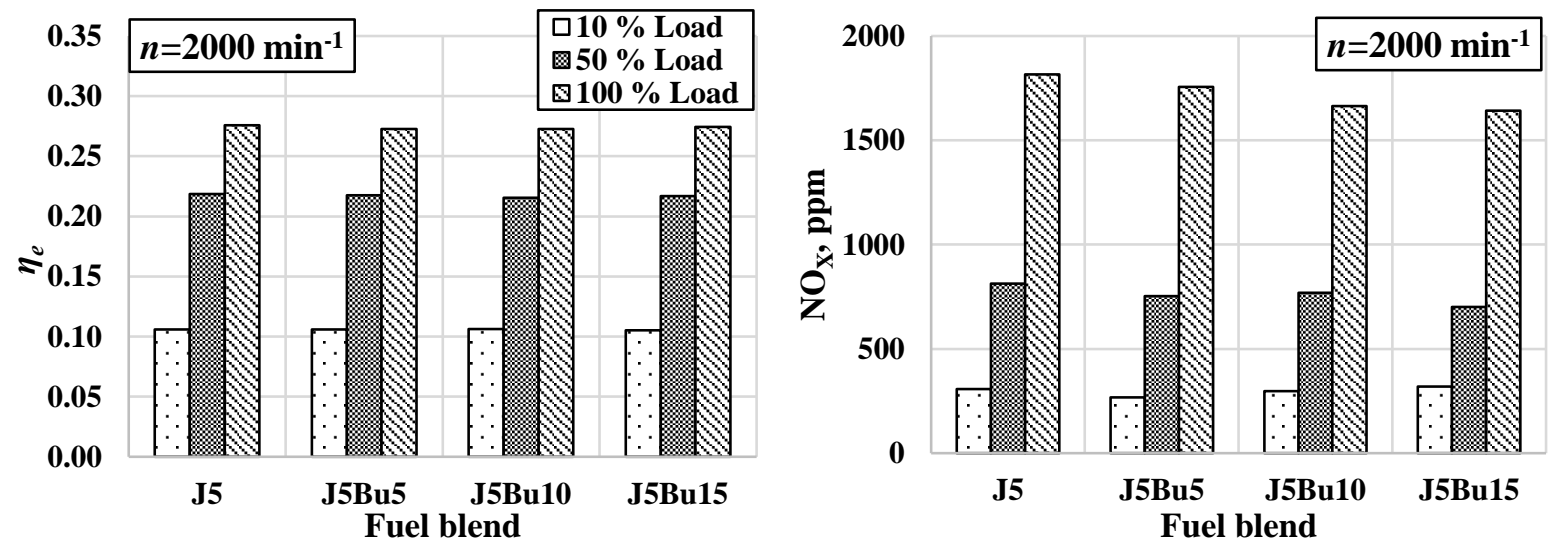

Fig. 2. Brake thermal efficiency $\left(\eta_{e}\right)$ and nitrogen oxide $\left(\mathrm{NO}_{\mathrm{x}}\right)$ as a function of engine load at $2000 \mathrm{~min}^{-1}$

Carbon monoxide is formed at local locations in the combustion chamber, where oxygen is completely lacking for the combustion reaction. Incompletely burned carbon atoms reduce the thermal energy conversion efficiency of fuels and increase carbon monoxide emissions. Ineffective combustion and low chamber temperatures release carbon monoxide and the unburned hydrocarbon emissions.

The dependencies of carbon monoxide (CO) emission on the engine load are shown in Fig. 3. When the engine is running at low load and using the three-component biofuel J5Bu5, J5Bu10 and J5Bu15 blends, the (CO) emission increases by 19-26\%, respectively, compared to the engine running on fuel $\mathrm{J} 5$ blend. In case at full engine load and using rich oxygenated blends J5Bu10 and J5Bu15, the carbon monoxide emission decreased by $13.3 \%$ and $14.5 \%$ in comparison to the engine running on fuel $\mathrm{J} 5$ blend. When operating on biofuel blend J5Bu5, the $\mathrm{CO}$ emission increases by $3 \%$. Similar trends were obtained, using n-butanol as an additive in a heavy-duty diesel engine with 5\%,10\%, 15\% of n-butanol content using multiple injections. Similar results showed that n-butanol addition decreased soot and CO emissions, but did not have a serious impact on BSFC [16].

Soot formation is able to progress at local locations in the fuel-saturated combustion chamber during pyrolysis of hydrocarbons. The smoke opacity of diesel engines depends on the cetane number of the fuel, the chemical composition, the amount of aromatic hydrocarbons, fuel injection and the quality of the combustible mixture, the diffusion process in the chamber and the complex mechanism of soot particle formation and their combustion burn reaction rate. Fig. 3 shows dependencies of smoke opacity on the exhaust of engine load. 

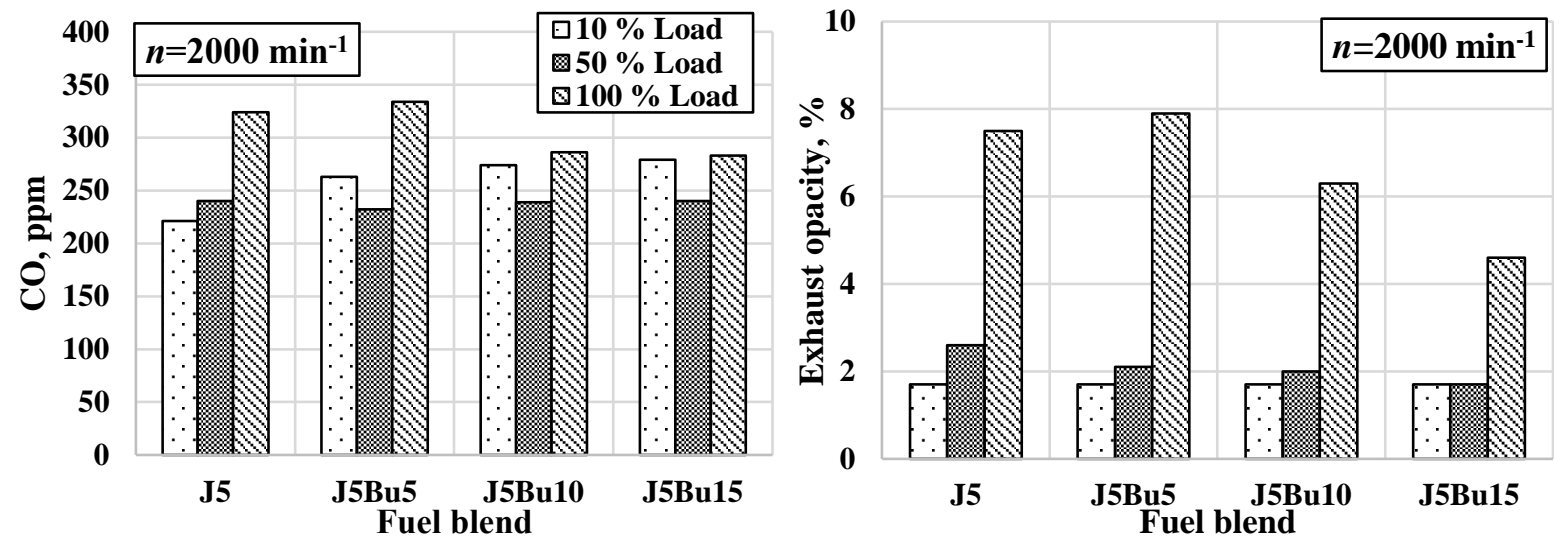

Fig. 3. Dependencies of carbon monoxide (CO) and smoke opacity of exhaust on engine load at $2000 \mathrm{~min}^{-1}$

At low engine load the smoke opacity remained lower in case of using all J5, J5Bu5, J5Bu10 and J5Bu15 fuel blends. The smoke opacity produced from biofuels J5Bu5, J5Bu 10 and J5Bu15 fuel blends sustained at lower levels over the average engine load. When running the engine on biofuel blends J5Bu10 and J5Bu15 at full load, the smoke opacity decreased by $19 \%$ and $63 \%$, respectively, compared to the cases of using J5 fuel blend. The lower smoke matches well with the test result findings of other researchers $[7 ; 14]$.

\section{Conclusions}

1. The brake mean fuel consumption, using three-component fuel blends, increased over the whole load range. At full engine load, with the three-component fuel J5Bu5, J5Bu10 and J5Bu15 blends, the break mean fuel consumption increased by $2.4 \%, 3.5 \%$, and $4.1 \%$, respectively, compared to fuel J5 blend.

2. Using the three-component biofuel J5Bu15 blend, the break thermal efficiency was $1 \%$ lower, compared to the engine running on fuel $\mathrm{J} 5$ blend, at full engine load.

3. The jet-biodiesel fuel (J5) blend developed the highest (1817 ppm) total emissions of nitrogen oxides. At full engine load and using different biofuel J5Bu5, J5Bu10 and J5Bu15 blends, the most environmentally and human harmful total emissions of nitrogen oxides decreased by $3.5 \%, 9.2 \%$ and $10.6 \%$, respectively.

4. When the engine was running at low load, the highest the carbon monoxide emissions were obtained with the engine running on biofuel J5Bu15 blend ( $279 \mathrm{ppm})$ and the lowest using the fuel J5 blend (221 ppm).

5. At the medium engine load using the three-component fuel J5Bu5, J5Bu10 and J5Bu15 blends, the smoke opacity was $23 \%, 30 \%$ and $52.9 \%$ lower, compared to the engine running on fuel J5 blend.

\section{References}

[1] Labeckas G., Slavinskas S., Vilutienè V. The effect of aviation fuel JP-8 and diesel fuel blends on engine performance and exhaust emissions. Journal of KONES, 2015, 22.

[2] McDonnell K.P., Ward S.M., McNulty P.B., Howard-Hildige R. Results of Engine and Vehicle Testing of Semirefined Rapeseed Oil. Transactions of the ASAE, Vol. 43(6), 2000, p. 1309-1316.

[3] EC, E. C. WHITE PAPER roadmap to a single European transport area towards a competitive and resource efficient transport system. COM (2011) 144 final, 2011.

[4] Labeckas G., Slavinskas S. Combustion phenomenon, performance and emissions of a diesel engine with aviation turbine JP-8 fuel and rapeseed biodiesel blends. Energy Conversion and Management, 2015, 105, pp. 216-229.

[5] Solmaz H., Yamık H., İçingür Y., Calam A. Investigation of the effects of civil aviation fuel Jet A1 blends on diesel engine performance and emission characteristics, Indian Journal of Engineering \& Materials Science Vol. 21, April 2014, pp. 200-206 
[6] Labeckas G., Slavinskas S. Combustion phenomenon, performance and emissions of a diesel engine with aviation turbine JP-8 fuel and rapeseed biodiesel blends. Energy Conversion and Management, 2015, 105: pp. 216-229.

[7] Arkoudeas P., et al. Study of using JP-8 aviation fuel and biodiesel in CI engines. Energy Conversion and Management, 2003, 44.7: pp. 1013-1025.

[8] Labeckas G., Slavinskas S., Mažeika M. The effect of ethanol-diesel-biodiesel blends on combustion, performance and emissions of a direct injection diesel engine. Energy Conversion and Management, 2014, 79, pp. 698-720.

[9] Gawron,B., et al. Performance and emission characteristic of miniature turbojet engine FED Jet A1/alcohol blend. Journal of KONES, 2016, 23.

[10] Labeckas G., Slavinskas S. The effect of rapeseed oil methyl ester on direct injection Diesel engine performance and exhaust emissions. Energy Conversion and Management, 2006, Vol. 47, Nr. 1314, pp. 1954-1967.

[11] Uyumaz A., et al. Experimental examination of the effects of military aviation fuel JP-8 and biodiesel fuel blends on the engine performance, exhaust emissions and combustion in a direct injection engine. Fuel Processing Technology, 2014, 128: pp. 158-165.

[12] Arkoudeas P., et al. Study of using JP-8 aviation fuel and biodiesel in CI engines. Energy Conversion and Management, 2003, 44.7: pp. 1013-1025.

[13] Lapuerta M., Hernandez J.J., Fernandez-Rodríguez D., Cova-Bonillo A. Autoignition of blends of n-butanol and ethanol with diesel or biodiesel fuels in a constant-volume combustion chamber. Energy, 2016, Vol. 118, pp. 613-621.

[14] Rakopoulos D.C., Rakopoulos C.D., Giakoumis E.G., Papagiannakis R.G., Kyritsis D.C. Influence of properties of various common bio-fuels on the combustion and emission characteristics of highspeed DI (direct injection) diesel engine: vegetable oil, bio-diesel, ethanol, n-butanol, diethyl ether. Energy 2014;73: pp. 354-366.

[15] Dogan O. The influence of $n$-butanol/diesel fuel blends utilization on a small diesel engine performance and emissions. Fuel 2011;90: pp. 2467-2472.

[16] Yao M., Wang H., Zheng Z., Yue Y. Experimental study of n-butanol additive and multi-injection on HD diesel engine performance and emissions. Fuel 2010;89: pp. 2191-2201. 